\title{
BMJ Open Unintended pregnancy, induced abortion and abortion care-seeking experiences among adolescents in Kinshasa, Democratic Republic of Congo: a cross-sectional study
}

\author{
Adesegun Fatusi (D) , ${ }^{1,2}$ Taylor Riley (D) , ${ }^{1}$ Patrick K Kayembe, ${ }^{3}$ Crispin Mabika ${ }^{4}$
}

To cite: Fatusi A, Riley T, Kayembe PK, et al. Unintended pregnancy, induced abortion and abortion care-seeking experiences among adolescents in Kinshasa, Democratic Republic of Congo: a crosssectional study. BMJ Open 2021;11:e044682. doi:10.1136/ bmjopen-2020-044682

- Prepublication history for this paper is available online. To view these files, please visit the journal online (http://dx.doi. org/10.1136/bmjopen-2020044682).

Received 23 October 2020 Accepted 13 July 2021

Check for updates

(C) Author(s) (or their employer(s)) 2021. Re-use permitted under CC BY-NC. No commercial re-use. See rights and permissions. Published by BMJ.

${ }^{1}$ Guttmacher Institute, New York, New York, USA

${ }^{2}$ School of Public Health, University of Medical Sciences, Ondo, Nigeria

${ }^{3}$ Department of Epidemiology \& Biostatistics, School of Public Health, University of Kinshasa, Kinshasa, Congo (the Democratic Republic of the) ${ }^{4}$ Department of Population Sciences and Development, University of Kinshasa, Kinshasa, Congo (the Democratic Republic of the)

Correspondence to Dr Adesegun Fatusi; adesegunfatusi@gmail.com

\section{ABSTRACT}

Objectives To estimate age-specific abortion incidence and unintended pregnancy in Kinshasa, Democratic Republic of Congo and compare care experiences between adolescents (15-19 years) and older women (20-49 years).

Design We used the age-specific variant of the Abortion Incidence Complications Method to estimate abortion and unintended pregnancy, with data from three primary sources: Health Facility Survey $(n=361)$ provided postabortion care (PAC) caseloads; Prospective Morbidity Survey $(n=1031)$ provided the age distribution and characteristics of women presenting for PAC and Health Professional Survey $(n=115)$ provided an estimate of the proportion of abortions resulting in facility-based treatment of complications. Bivariate $\left(\chi^{2}\right.$, t-test) and multivariable (binary logistic regression, Cox proportional hazard) analyses were used to compare abortion care experiences.

Setting Health facilities proving PAC in Kinshasa.

Participants Women who presented to PAC facilities with abortion complications and their care providers.

Primary and secondary outcome measures The primary measures were abortion incidence and proportion of pregnancies unintended. The secondary measures were the odd of reporting specific abortion care experiences.

Results Adolescents had an estimated 27590 induced abortions, constituting $18.8 \%$ of abortions in Kinshasa in 2016. Adolescents had the lowest abortion rate among women less than 35 years (55.2/1000 women) but the highest rate among ever sexually active women (138.4/1000) and recently sexually active women (167.2/1000). Also, adolescents had the highest abortion ratio (82.4/100 live births), proportion of pregnancies unintended (80\%) and proportion of unintended pregnancies ending in abortion (49\%). Compared with older women, adolescents had higher odds of reporting pregnancy unintendedness (adjusted OR, AOR 1.36, $95 \% \mathrm{Cl} 1.75$ to 2.24), seeking abortion at later than first trimester (AOR 1.34, 95\% Cl 1.09 to 1.63) and from nonmedical professionals (AOR 1.68, 95\% Cl 1.31 to 2.14 ), and not using contraceptives before pregnancy (AOR 2.23, $95 \% \mathrm{Cl} 2.77$ to 3.43 ) or postabortion (AOR $2.46,95 \% \mathrm{Cl}$ 1.87 to 3.29 ).
Strengths and limitations of this study

- This study provides the first age-specific estimates of unintended pregnancy and abortion for Kinshasa, Democratic Republic of Congo.

- The underlying data on the number of postabortion care (PAC) patients comes from a census of PAC providing facilities in Kinshasa, and the weighted age and subgroup distribution of PAC patients is from a representative sample of PAC-providing facilities.

- In the absence of an age-specific multiplier, we uniformly applied a nationally obtained multiplier from a representative sample of PAC cases to all the age groups to obtain the age-specific induced abortions estimates: this may bias the estimate for specific age groups.

Conclusions Interventions are needed to reduce unintended pregnancy among adolescents in Kinshasa and improve their abortion care experiences.

\section{INTRODUCTION}

Unsafe abortion is a public health challenge that is associated with at least $8 \%$ of global maternal deaths. ${ }^{1}$ The burden of unsafe abortion is highest in countries with restrictive abortion laws and approximately 97\% of unsafe abortions and nearly all abortionrelated deaths occur in low-income and middle-income countries (LMICs). ${ }^{2}$ Africa, which has the highest risk of abortion-related deaths globally, ${ }^{2}$ presents striking statistics: most African countries have restrictive laws ${ }^{3}$ and induced abortions occur mostly in a clandestine manner, with the result of over threequarters $(75.6 \%)$ of the estimated annual 6.86 million abortions in Africa being unsafe. ${ }^{2}$ While we recognise that the term 'abortion' technically covers both induced abortion and spontaneous abortion (miscarriages), unless 
otherwise specified, abortion as used in this paper refers to induced abortion.

Democratic Republic of Congo (DRC), the third most populous country in Africa, previously had a restrictive penal code that forbade abortion under any circumstances but domesticated the African Charter on Human and People's Rights on the Rights of Women (Maputo Protocol) that permits abortion on some health grounds in 2018. ${ }^{4}$ However, abortion remains largely clandestine in DRC. ${ }^{5}$ With an estimated population of 12 million in 2016, Kinshasa, the capital of DRC, is the second most populous and densest city in sub-Saharan Africa. ${ }^{6}$ Kinshasa has a high level of unmet need for contraception $^{7-9}$ and many women undergo abortions to meet their fertility aspirations. ${ }^{5810}$ Two studies involving different methodological approaches - the Confidante Method ${ }^{10}$ and Abortion Incidence Complications Method (AICM) ${ }^{5}$ similarly estimated Kinshasa's abortion rate as 55-56 per 1000 women aged 15-49 for 2015/2016. While some small-scale studies suggest a substantial level of adolescent abortion in Kinshasa, ${ }^{11-13}$ adolescent-specific abortion estimates are lacking.

Globally, studies on adolescent-specific abortion measures are rare, despite indications that adolescents contribute significantly to the abortion burden and are potentially at greater risks of complications associated with lower rates of healthcare access. ${ }^{14} 15$ As a 2019 review to mark the 25th anniversary of the International Conference on Population and Development notes, 'Data on the specific levels and trends in abortion measures that are specific to adolescents are scarce, particularly among LMICs. ${ }^{16}$ Studies comparing abortion measures for adolescents and older women are also scarce and the findings from the few existing studies vary considerably. ${ }^{17}$ In Africa, compared with older women (20-49 years), higher adolescent abortion rates have been reported for Nigeria, ${ }^{18}$ but lower rates for Gabon, Ghana, Republic of Congo and Zimbabwe. ${ }^{17} 18$

Among African countries, recent adolescent-specific abortion estimates are only available for Ethiopia, ${ }^{19}$ Uganda $^{20}$ and Zimbabwe. ${ }^{21}$ These recent papers, unlike previous works, adjusted for sexual activity and, therefore, provide estimates specifically for sexually active adolescents and older women, which make for a more valid comparison between the age groups. While sexually active adolescents had a higher abortion rate compared with older women in Ethiopia ${ }^{19}$ and Uganda, ${ }^{20}$ the reverse was the case in Zimbabwe. ${ }^{21}$ The differential findings probably reflect contextual sexual and reproductive health (SRH) dynamics and highlight the need for studies in different geographies. So far, no comparison of abortion incidence for adolescents and older women exist in the literature for Kinshasa, DRC, as age-specific estimates are lacking. Generating age-specific abortion and unintended pregnancy measures is crucial for understanding the burden of unintended pregnancy and abortion among adolescents and for advocating for relevant interventions to improve their health and well-being. ${ }^{9}$
Comparing adolescent and non-adolescent abortionrelated care experiences, including post-abortion care (PAC), is also important as the experiences have significant implications for the health outcomes and well-being of the women seeking abortions, as well as for health systems treating abortion complications. Some of the existing studies suggest that the quality of care and the experiences of adolescents in the context of abortion may differ significantly from that of older women ${ }^{19} 22$ but these findings are by no means universal and vary by geographical and socioeconomic contexts. So far, no published studies have compared the abortion care experiences of adolescents and older women in Kinshasa, DRC. Analysing differences that may exist in the abortion care experiences of adolescents and older women can generate relevant information for appropriate interventions to address any potential adolescent-specific barriers to relevant care.

This study aims to address the existing evidence gap relating to age-specific analyses of abortion incidence and abortion care experience in Kinshasa, DRC. Our primary objective is to estimate and compare unintended pregnancy and abortion incidence for adolescents and older women in Kinshasa. Second, we compare the abortion care experiences of adolescents and older PAC patients.

\section{METHODS}

\section{Study design and data sources}

We used the age-specific variant of $\mathrm{AICM}^{1920}$ to indirectly estimate abortion and unintended pregnancy for adolescents (15-19) and older women (20-49). Developed in the early 1990s, the AICM has been used to estimate abortion incidence for 23 LMICs as of $2017 .{ }^{23}$ The age-specific AICM uses three primary data sources: Health Facility Survey (HFS), which provides PAC caseloads; Prospective Morbidity Survey (PMS), which provides the age distribution and characteristics of women presenting for PAC and their care-seeking behaviour and experience; and, Health Professional Survey (HPS) that provides an estimate of the proportion of abortions that results in facility-based treatment of abortion complications, the inverse of which serves as the multiplier or adjustment factor in the AICM approach.

The current study is based on data collected in 2016 to estimate abortion incidence for Kinshasa. The HFS was conducted in a representative sample of 361 facilities with the capacity to provide PAC. The PMS was prospectively conducted for 30 days in 223 of the 361 HFS facilities with data from 1,031 PAC patients. The HPS was a purposive sample of 115 health professionals who are knowledgeable about abortion practices in Kinshasa. Details of the study design have previously been published by Chae $e t a l$, including various steps taken to minimise bias in the data collection process. ${ }^{5}$ 


\section{Patient and public involvement}

We did not directly involve abortion patients in the study planning but the original data collection that provided the foundation for this study sought and received guidance for study planning and results dissemination from a Technical Advisory Committee, which included community representatives and technical experts, and the current study also received similar guidance.

\section{Data analysis}

\section{Abortion measures}

Our age-specific estimation of abortion incidence involved three key sequential steps. First, we applied the age distribution of PAC patients from the PMS to the total PAC caseloads reported by Chae et a $\tilde{e}$ for women age 15-49 to obtain the PAC caseloads for 5-year age groups. Second, recognising that PAC caseloads include both induced and spontaneous abortion (miscarriages), we calculated the number of treated second-trimester miscarriages through a two-step process and subtracted the obtained figure from the PAC caseloads. The initial step involved estimating second-trimester miscarriages requiring treatment with the assumption that only second trimester miscarriages (13-22 weeks) would result in facility-based care as is the practice in the AICM approach. ${ }^{23}$ Clinical data from Harlap et al show that second-trimester miscarriages constitute $2.9 \%$ of all known pregnancies and $3.41 \%$ of live births ${ }^{24}$; applying the age-specific life tables developed based on that data by Sully et $\mathrm{al}^{19}$ we estimated the number of second-trimester miscarriages for the 5-year age groups. Then, in line with previous AICM studies ${ }^{23}$ we estimated the proportion of second-trimester miscarriages that received facility care as equal to the agespecific proportion of facility-based deliveries obtained from the 2013-2014 Demographic and Health Survey (DHS) data for Kinshasa. ${ }^{25}$ Subtracting the number of treated second-trimester miscarriages from the total agespecific PAC caseloads resulted in the age-specific PAC cases attributable to induced abortion.

Third, we estimated abortions that did not result in facility-based care by using the multiplier, which is the inverse of the proportion of all abortions that result in complications and facility-based care as estimated in the HPS. As age-specific multipliers are not available, we applied the overall multiplier generated by Chae $e t a \tilde{l}$ uniformly across the age groups to estimate the number of induced abortions for each age group. We then summed the estimates obtained for all age groups and proportionally adjusted the age-specific estimates to ensure that the sum equalled the figure previously reported by Chae $e t a \tilde{l}$ for women age 15-49 years.

As standardly defined, we calculated the age-specific abortion incidence rate as the number of abortions per 1000 women per age group and abortion ratio as the number of abortions per 100 live births for each age group. To address age-related differential sexual activity, we calculated abortion incidence for women who ever had sex and women with recent sexual activity (defined as sex within 12 months before the survey). ${ }^{19} 20$

\section{Unintended pregnancy}

We calculated unintended pregnancy as the sum of three events: (1) induced abortion (explained above), (2) unintended births, defined as births that were unplanned at the time of conception (either unwanted or mistimed) and obtained from the DHS and (3) unintended pregnancies that ended in miscarriage. The number of unintended births was obtained by multiplying the age-specific proportion of unplanned births documented in the DHS report by the number of age-specific births, which was calculated by applying age-specific fertility rates from the 2013-14 DRC DHS ${ }^{25}$ to age-specific population estimates of women of reproductive age (15-49 years) in Kinshasa. ${ }^{26}$ Based on the work of Leridon and Helzner ${ }^{27}$ and in line with the AICM approach, ${ }^{23}$ unintended pregnancies ending in miscarriage were calculated as the sum of $20 \%$ of unplanned live births and $10 \%$ of induced abortions. Intended pregnancies were calculated as the sum of planned births (obtained by subtracting unplanned births from the total number of births) and miscarriages from intended pregnancies (estimated as $20 \%$ of planned births). ${ }^{27}$

\section{Abortion-related experiences}

Using the PMS data of women receiving PAC (following either induced abortions or miscarriages), we compared the background characteristics and experiences of adolescent and older women regarding abortion. Specifically, we compared the sociodemographic and reproductive characteristics for adolescents and older women using $\chi^{2}$ and compared the mean number of days to reach PAC (to assess a possible delay in reaching care) using t-test. We further compared adolescents and older PAC patients using multivariable analyses for nine abortion-related and care experiences: (1) history of previous abortion; (2) contraception at the time of pregnancy; (3) intendedness of index pregnancy; (4) gestational age at abortion (first trimester vs later); (5) interference with pregnancy (inducing abortion); (6) professional status of the abortion service provider (medical professionals vs others); (7) severity of postabortion complication (none/mild vs moderate/severe); (8) delay in reaching care (sum of the total number of days taken to decide to seek care and to reach the first health facility) and (9) provision of postabortion contraceptives by PAC provider. We controlled for marital status, education, economic level (poor or nonpoor status) based on household wealth index, previous pregnancy and pregnancy intention (except when pregnancy intendedness was the dependent variable) in each multivariable model. We used binary logistic regression for multivariable analyses and obtained the adjusted OR (AOR) and the $95 \%$ CI, except in the case of the number of days taken to reach PAC where we used a Cox proportional hazard model and obtained the hazard ratio (HR) 


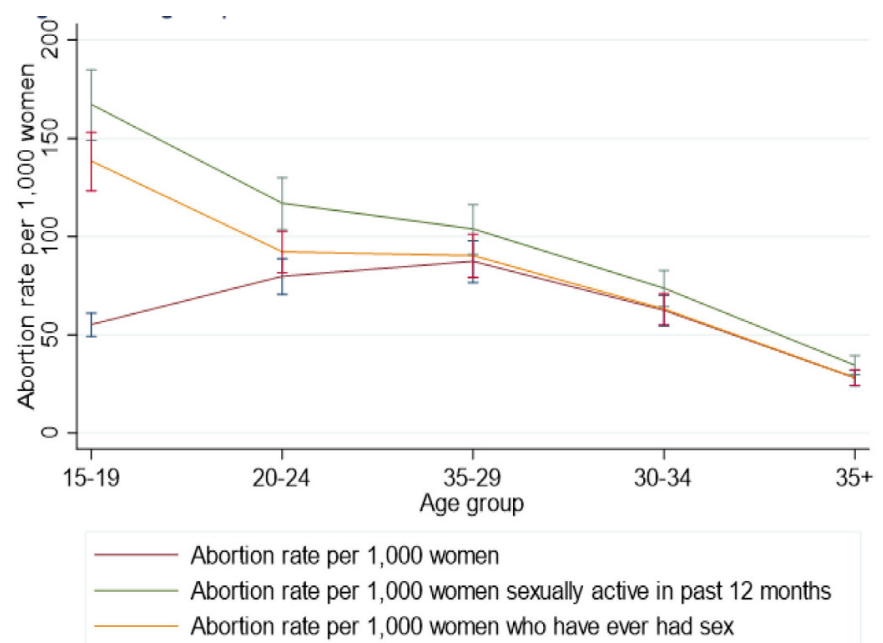

Figure 1 Abortion estimates by age group in Kinshasa, DRC, for all women, ever-sexually active women and recently sexually active women, 2016. Abortion rate per 1000 women; abortion rate per 1000 women sexually active in past 12 months; abortion rate per 1000 women who have ever had sex. DRC, Democratic Republic of Congo.

and $95 \%$ confidence interval (CI). Analyses were undertaken using Stata V.16 and SPSS V.24.

\section{RESULTS}

\section{Incidence of abortion}

An estimated 27590 induced abortions occurred among adolescents, constituting $18.8 \%$ of the 146713 abortions in Kinshasa in 2016: this proportion is similar to the percentage of women of reproductive age (15-49 years) who are adolescents $(19.5 \%)$. Adolescents have the lowest abortion rate ( 55.2 per 1000 women) among women less than 35 years of age. However, restricting the sample to only sexually active women, the abortion rate shows an inverse relationship with age, and adolescents have the highest rate among all women of reproductive age (figure 1). The abortion rate is $138.4 / 1000$ for adolescents who ever had sex and 167.2/1000 for recently sexually active adolescents. In comparison, for older age groups, the abortion rate ranges from $28.2 / 1000$ to $92.3 / 1000$ for those who ever had sex, and from 34.6/1000 to $117.0 / 1000$ for recently sexually active women. The abortion ratio also shows an inverse relationship with age, and adolescents have the highest ratio (82.4 per 100 live births vs 33.1/100-56.2/100 live births for older women).

\section{Unintended pregnancy}

An estimated 70733 pregnancies occurred among adolescents-about $12.5 \%$ of the 563064 pregnancies estimated for Kinshasa in 2016. Eighty per cent of pregnancies among adolescents are unintended compared with the lower range of 53\%-67\% for older age groups (figure 2). The proportion of unintended pregnancies that ended in abortion shows an inverse relationship with age, decreasing progressively from $49 \%$ for age $15-19$ years to $37 \%$ for age $\geq 35$ years. Unlike in older age groups (age

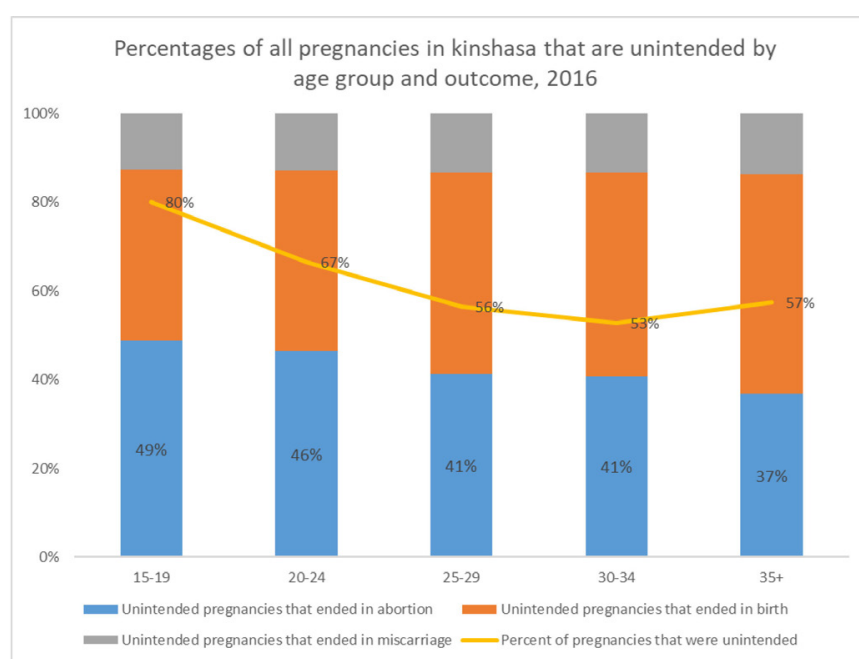

Figure 2 Percentage of all pregnancies in Kinshasa, DRC, that are unintended by age group and outcome, 2016; unintended pregnancies that ended in abortion; unintended pregnancies that ended in birth; unintended pregnancies that ended in miscarriage; per cent of pregnancies that were unintended. DRC, Democratic Republic of Congo.

25-49 years), the proportion of unintended pregnancies ending in abortion is higher than those ending in births among adolescents (49\% vs 39\%) and other young people age $20-24$ (46\% vs $41 \%$ ).

\section{Abortion-related experiences}

Compared with older women aged 20-49 years, bivariate analysis shows that adolescent PAC clients were significantly less likely to be in union ( $38 \%$ vs $63 \%, \mathrm{p}<0.001)$ but significantly more likely to come from poor households $(48 \%$ vs $39 \%, \mathrm{p}<0.001)$ and have postprimary education $(19 \%$ vs $10 \%, \mathrm{p}<0.001)$ (table 1$)$. Adolescents are less likely to use contraceptives before pregnancy ( $16 \%$ vs $30 \%, \mathrm{p}<0.001)$, report their pregnancy as being intended ( $13 \%$ vs $30 \%, \mathrm{p}<0.001)$, or receive postabortion contraceptives ( $9 \%$ vs $17 \%, \mathrm{p}<0.001$ ). However, adolescents were more likely to report the index pregnancy as induced ( $51 \%$ vs $40 \%, \mathrm{p}<0.001)$ as well as seek abortion at a later gestation age than the first trimester $(24 \%$ vs $19 \%, \mathrm{p}=0.001)$ and from non-medical professionals $(63 \%$ vs $55 \%, \mathrm{p}=0.002)$. A higher proportion of adolescents compared with older PAC patients also reported experiencing moderate/severe complications $(69 \%$ vs $61 \%$, $\mathrm{p}<0.001)$ or that the index pregnancy resulted from forced sex ( $10 \%$ vs $4 \%, \mathrm{p}<0.001)$. Adolescents and older women did not significantly differ in the time taken to reach PAC services ( 4.0 days vs 4.4 days, $\mathrm{p}=0.214$ )

Multivariable analysis (figure 3) shows that controlling for the effect of other factors, adolescent PAC patients have significantly higher odds of unintended pregnancy (AOR 1.36, 95\% CI 1.75 to 2.24), not using contraceptives before pregnancy (AOR 2.23, 95\% CI 2.77 to 3.43), but lower odds of history of previous abortion (AOR $0.78 ; 95 \%$ CI 0.63 to 0.96 ) compared with older PAC patients. Also, adolescent PAC patients have higher odds 
Table 1 Sociodemographic characteristics of postabortion care patients, Kinshasa 2016

\begin{tabular}{|c|c|c|c|}
\hline $\begin{array}{l}\text { Adolescents (15-19) } \\
\mathrm{N}=795\end{array}$ & & (20-49) & $\begin{array}{l}\text { All women (15-49) } \\
\mathrm{N}=4990\end{array}$ \\
\hline$\%$ & $\mathbf{N}$ & $\%$ & $\mathbf{N}$ \\
\hline
\end{tabular}

1. Sociodemographic characteristics

Socioeconomic status

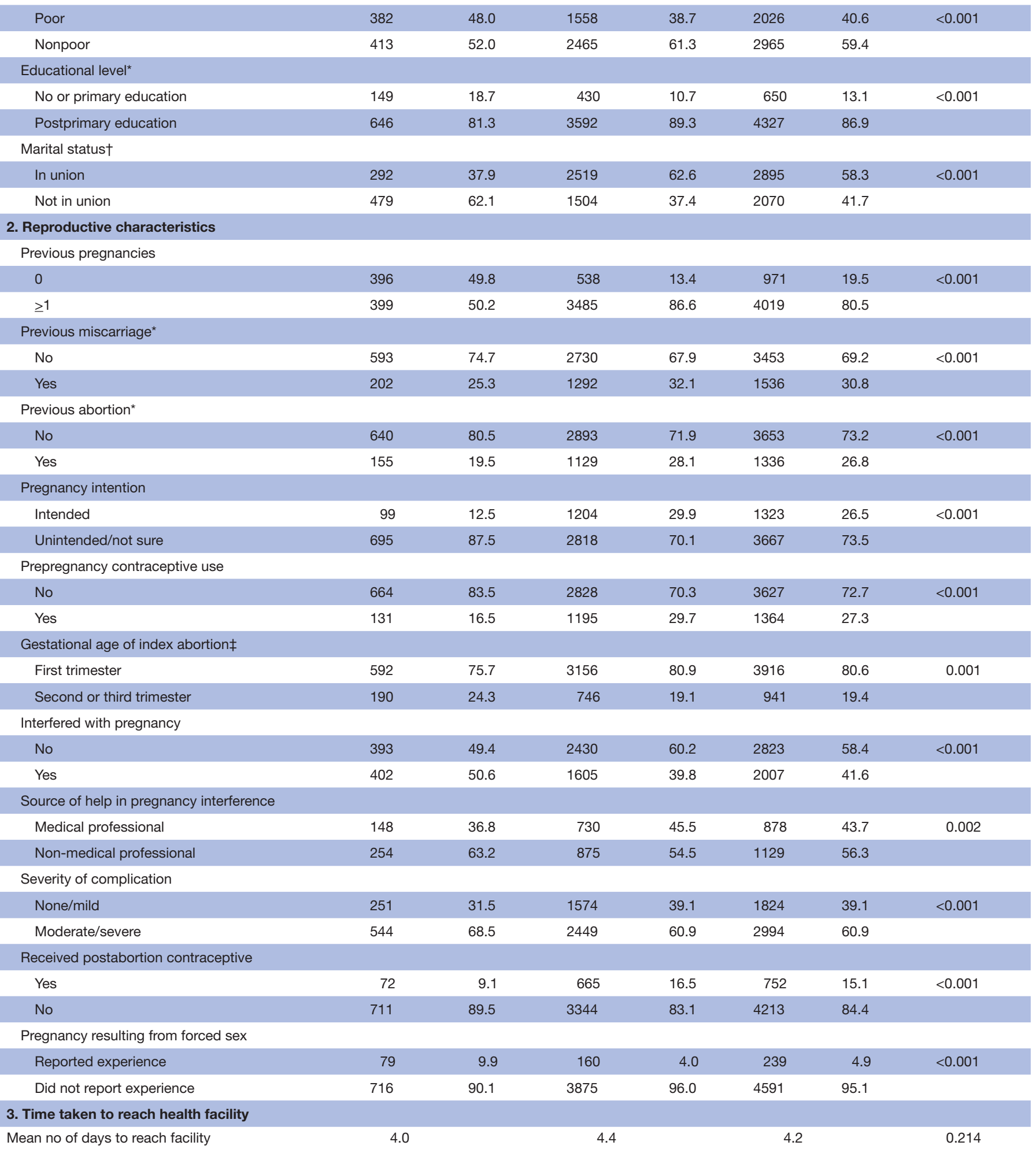

*1 missing respondent each from educational level, previous miscarriage, previous abortion and pregnancy intention for older women group.

†23 missing respondents from marital variable for adolescents.

$\neq 13$ missing respondents for gestational age at abortion for adolescents and 120 for older women category. 


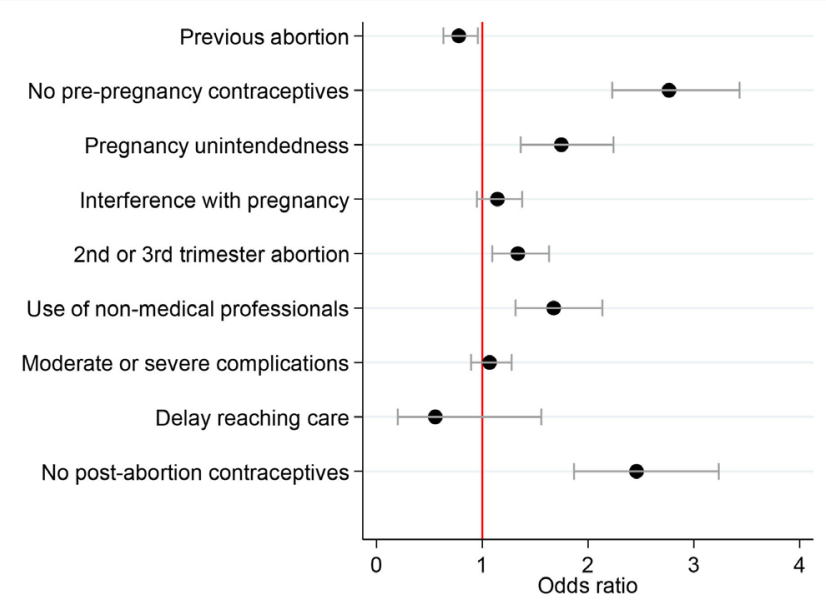

Figure 3 Adjusted ORs, HRs and 95\% Cls of abortion care experiences among adolescent postabortion care patients as compared with older postabortion care patients in Kinshasa, DRC, 2016. DRC, Kinshasa.

of seeking abortion at later gestational age (second or third trimester) (AOR 1.34,95\% CI 1.09 to 1.63) and from non-medical professionals (AOR 1.68, 95\% CI 1.31 to 2.14) and not receiving postabortion contraceptives (AOR 2.46, 95\% CI 1.87 to 3.29). However, adolescents and older PAC patients did not significantly differ in terms of interfering with the index pregnancy (induced abortion), experiencing postabortion complications and the time taken to reach PAC services.

\section{DISCUSSION}

This study, to the best of our knowledge, provides the first age-specific estimates of unintended pregnancy and abortion for Kinshasa, DRC. Regarding abortion among women aged less than 35 years, adolescents recorded the lowest rate in this study. However, when we considered only women who have ever had sex and thereby exposed to the possibility of pregnancy, adolescents have the highest rate of abortion among ever sexually active and recently sexually active women, similar to the findings in Ethiopia ${ }^{19}$ and Uganda ${ }^{20}$ but contrary to the findings in Zimbabwe. ${ }^{21}$ Compared with their peers in Zimbabwe $(15.9 / 1000),{ }^{21}$ Uganda $(76.1 / 1000)^{20}$ and Ethiopia $(90.7 / 1000),{ }^{19}$ the abortion rate is substantially higher for recently sexually active adolescents in Kinshasa (167.2/1000).

Compared with older women, adolescents have a higher rate of unintended pregnancy in Kinshasa. The proportion of pregnancy that is unintended is also substantially higher for adolescents in Kinshasa (80\%) compared with their counterparts in Ethiopia, ${ }^{19}$ Uganda $^{20}$ and Zimbabwe $^{21}$ where about half of all pregnancies or less are unintended-and likely contributed to the higher adolescent abortion rate in Kinshasa. Approximately half of the unintended pregnancy among adolescents in Kinshasa ended in abortion compared with less than a fifth of such pregnancies among adolescents in Uganda ${ }^{20}$ and Zimbabwe. ${ }^{21}$ While the proportion of unintended pregnancies ending in abortion is higher for adolescents compared with older women in Kinshasa, the proportion did not vary systematically by age in Uganda. ${ }^{20}$ Unintended pregnancy in Kinshasa, as our findings show, is more likely to result in abortion among adolescents and other young people (age 15-24) than in births unlike the picture in older women. The abortion ratio of 82.4 per 100 live births for adolescents in Kinshasa, which implies that approximately four abortions occur among adolescents for every five births, is substantially higher than the ratio for older women in Kinshasa and more than double the ratio of $\leq 31.1 / 100$ live births for adolescents in Ethiopia $^{19}$ and Zimbabwe. ${ }^{21}$

The higher rate of unintended pregnancy among adolescents in Kinshasa compared with older women may likely be explained by differential contraceptive behaviour. As the 2013-2014 DRC DHS reports, adolescents have the lowest rate of contraceptive use among women aged less than 45 years. ${ }^{25}$ Studies have also shown that adolescents in DRC $^{28}$ and Kinshasa ${ }^{29}$ have a higher unmet need for contraceptives. Globally, adolescents have a higher level of unmet need for contraceptives as a result of demandside barriers (contraceptive-seeking behaviour), supplyside barriers (health service factors) and structural and environmental barriers such as unsupportive social norms and policies. ${ }^{30} 31$ Specifically for DRC, research findings indicate that existing family planning services have gaps and inadequacies regarding adolescents' needs ${ }^{32}$ and that cultural perspectives and social norms against premarital and adolescent sexual engagement are deeply rooted. ${ }^{33}$ The strong social stigma associated with premarital or out-of-union pregnancy is likely to have also contributed significantly to the high adolescent abortion ratio in Kinshasa. As a qualitative study reported, young people in Kinshasa have concerns that pre-marital pregnancy would bring dishonour to their families and may, therefore, seek abortion clandestinely in case of unintended pregnancy. ${ }^{34}$

It is important to emphasise that our findings relate to only Kinshasa - the national capital of DRC and a highly urbanised area, and not the entire country. The abortion estimates for DRC as a whole would likely have been much lower as most other parts of the country outside Kinshasa are far less urbanised and abortion rates are generally higher in urban settings. ${ }^{18}$ Our focus on Kinshasa alone also likely explains the higher abortion estimates we obtained compared with the figures for adolescents in more nationally-oriented studies in Ethiopia, ${ }^{19}$ Uganda $^{20}$ and Zimbabwe. ${ }^{21}$

Regarding abortion-related care experiences, our findings show that adolescent PAC clients have less desired abortion care experiences compared with older women in terms of seeking an abortion later than the first trimester and from non-medical professionals and are less likely to use contraceptives before pregnancy or receive postabortion contraceptives. Although several authors have reported that adolescents may face more barriers to SRH care $^{3031}$ and receive a lower quality of maternal health services, ${ }^{35}$ the findings concerning PAC varied. ${ }^{20}{ }^{21}$ For 
example, while Riley $e t a l^{21}$ reported that adolescent PAC patients are $21 \%$ more likely to experience a delay in reaching care in Zimbabwe compared with older women, Sully $e t a l^{20}$ recorded no significant difference between adolescents and older women in this respect in Uganda. The Ugandan study also found no significant difference between adolescents and older women concerning the experience of unintended pregnancy, the gestational age of seeking an abortion, the use of non-medical professionals for abortion services, or in receiving postabortion contraceptive services. ${ }^{20}$

This study has some limitations. First, in the absence of an age-specific multiplier, we used a uniform multiplier in estimating abortions by age groups: this may bias the estimate for specific age groups as the possibility of the occurrence of a complication and access to treatment may vary by age. Specifically, if the multiplier-'the number of women without complications or with untreated complications for every woman with a treated complication, ${ }^{, 19}$ is higher for adolescents than for older ages our abortion rate for adolescents would be an underestimate. While no significant difference was recorded in the time taken by adolescents and older women to reach PAC in this study, a higher proportion of adolescents compared with older women experienced moderate/severe complications. Second, our findings regarding care-seeking experiences may not be generalisable to all abortion experiences as PAC caseload consists of both miscarriages and induced abortion cases, and the care-seeking behaviours may differ for the two groups. Also, women who had abortions but did not experience complications, those who failed to seek facility care for abortion complications or those who died from abortion complications are excluded from the PAC caseloads. Thus, our findings cannot be generalised for induced abortion complications. Third, self-reported information from PAC patients may be liable to social desirability and other forms of response bias. The findings that adolescents are less likely to report their pregnancy as being intended and more likely to report the index pregnancy as induced may indicate a low level of social desirability bias, if at all.

Our findings imply the need to prioritise adolescent SRH issues in Kinshasa. While Congo DRC has several policies and programmes with relevant focus on adolescent SRH issues, including the National Multisectoral Plan on Family Planning (2014-2020) and school-based sexuality education programme (Family Life Education) programme, the country faces formidable challenges in terms of implementation, resulting in suboptimal effectiveness. ${ }^{36}{ }^{37}$ Thus, the country needs to strengthen the implementation of policies and programmes to enable adolescents to overcome various barriers to accessing modern contraceptives and thereby reduce unintended pregnancy and the associated abortion. Among others, efforts should be directed towards expanding modern family planning services and improving the friendliness and responsiveness of services to adolescents. Evidencedriven behaviour change communications are needed to improve adolescent contraceptive-seeking behaviour and positively impact SRH-related social norms. Also, there is a need to rigorously implement the domesticated Maputo protocol to improve access to safe abortion as well as abortion-related care experiences and outcomes for adolescents as well as older women. Overall, considerable efforts should be dedicated to strengthening the capacity of health and related social systems to be more adolescent responsive: meaningful involvement of adolescents and adolescent-serving organisations in relevant policy and programme decisions are important in this regard.

Acknowledgements The authors are grateful to Akinrinola Bankole, Alanna Galati, Sarah Keogh, Sophia Sadinsky, and Elizabeth Sully for their review of the manuscript. We are also grateful to Florby Dorme, Meg Schurr and Madison Poore for support services.

Contributors AF led the conceptualisation of the research, and TR, PKK and CM participated in the process. TR and AF analysed the data. AF wrote the original draft of the manuscript; TR, PKK and CM participated in reviewing and editing the draft. PKK and CM played leadership roles in the original data collection exercise.

Funding This study was made possible by the Dutch Ministry of Foreign Affairs (Activity \#4000000282) and UK Aid from the UK Government (project \#203177-101).

Disclaimer The views expressed are those of the authors and do not necessarily reflect the positions and policies of the donors.

Competing interests None declared.

Patient and public involvement Patients and/or the public were not involved in the design, or conduct, or reporting, or dissemination plans of this research.

Patient consent for publication Not required.

Ethics approval We obtained ethical approval from the institutional ethics board of the Guttmacher Institute (10 November 2015, DHHS identifier IRB00002197) and from the University of Kinshasa School of Public Heath Ethics Committee (27 December 2015, approval number ESP/CE/010B/2015).

Provenance and peer review Not commissioned; externally peer reviewed.

Data availability statement Data are available on reasonable request. Deidentified versions of the raw Health Facility Survey, Prospective Morbidity Survey and Health Professional Survey Health datasets used by the authors are available from the Guttmacher Institute on reasonable request to researchers who wish to use the data for scholarly analysis. To discuss obtaining copies of these datasets, please contact popcenter@guttmacher. org with the detailed protocol for your proposed study, and information about the funding and resources you have to carry out the study.

Open access This is an open access article distributed in accordance with the Creative Commons Attribution Non Commercial (CC BY-NC 4.0) license, which permits others to distribute, remix, adapt, build upon this work non-commercially, and license their derivative works on different terms, provided the original work is properly cited, appropriate credit is given, any changes made indicated, and the use is non-commercial. See: http://creativecommons.org/licenses/by-nc/4.0/.

\section{ORCID iDs}

Adesegun Fatusi http://orcid.org/0000-0002-3893-8024

Taylor Riley http://orcid.org/0000-0002-4963-0455

\section{REFERENCES}

1 Say L, Chou D, Gemmill A, et al. Global causes of maternal death: a WHO systematic analysis. Lancet Glob Health 2014;2:e323-33.

2 Ganatra B, Gerdts C, Rossier C, et al. Global, regional, and subregional classification of abortions by safety, 2010-14: estimates from a Bayesian hierarchical model. Lancet 2017;390:2372-81.

3 Lavelanet AF, Schlitt S, Johnson BR, et al. Global abortion policies database: a descriptive analysis of the legal categories of lawful abortion. BMC Int Health Hum Rights 2018;18:44.

4 Président de la Cour Constitutionnelle. Circulaire Relative La Mise En Exécution Des Dispositions de l'Article 14 Du Protocole La Charte 
Africaine Des Droits de l'homme et Des Peuples Relative Aux Droits de La Femme En Afrique, 2018. Available: http://www.leganet.cd/ Legislation/JO/2018/jos.05.06.2018.o.pdf [Accessed 7 Jun 2019]

5 Chae S, Kayembe PK, Philbin J, et al. The incidence of induced abortion in Kinshasa, Democratic Republic of Congo, 2016. PLoS One 2017;12:e0184389.

6 World Bank. Democratic Republic of Congo urbanization review: productive and inclusive cities for an emerging Democratic Republic of Congo. Washington, DC: World Bank, 2018. https:// openknowledge.worldbank.org/bitstream/handle/10986/28931/ 9781464812033.pdf? sequence $=2$

7 Kwete D, Binanga A, Mukaba T, et al. Family planning in the Democratic Republic of the Congo: encouraging momentum, formidable challenges. Glob Health Sci Pract 2018;6:40-54.

8 Bankole A, Kayembe P, Chae S, et al. The severity and management of complications among postabortion patients treated in Kinshasa health facilities. Int Perspect Sex Reprod Health 2018;44:1-9.

9 Ahmed S, Choi Y, Rimon JG, et al. Trends in contraceptive prevalence rates in sub-Saharan Africa since the 2012 London Summit on family planning: results from repeated cross-sectional surveys. Lancet Glob Health 2019;7:e904-11.

10 Ishoso DK, Tshefu AK, Delvaux T, et al. Extent of induced abortions and occurrence of complications in Kinshasa, Democratic Republic of the Congo. Reprod Health 2019;16:49.

11 Lupwana K. Clandestine and risk abortions of female adolescents by self-medication in the outskirts of Kinshasa: vulnerability factors. Paper presented at the sixth African population Conference, Ouagadougou, Burkina Faso: sixth African population conference, 2011. Available: https://uaps2011.princeton.edu/abstracts/110572 [Accessed 9 Jul 2019].

12 Paluku LJ, Mabuza LH, Maduna PMH, et al. Knowledge and attitude of schoolgirls about illegal abortions in Goma, Democratic Republic of Congo. Afr J Prim Health Care Fam Med 2010;2:a78.

13 Kayembe PK, Fatuma AB, Mapatano MA, et al. Prevalence and determinants of the use of modern contraceptive methods in Kinshasa, Democratic Republic of Congo. Contraception 2006; 74:400-6.

14 Shah I, Ahman E. Age patterns of unsafe abortion in developing country regions. Reprod Health Matters 2004;12:9-17.

15 Shah IH, Ahman E. Unsafe abortion differentials in 2008 by age and developing country region: high burden among young women. Reprod Health Matters 2012;20:169-73.

16 Liang M, Simelane S, Fortuny Fillo G, et al. The state of adolescent sexual and reproductive health. J Adolesc Health 2019;65:S3-15.

17 Sedgh G, Finer LB, Bankole A, et al. Adolescent pregnancy, birth, and abortion rates across countries: levels and recent trends. $J$ Adolesc Health 2015;56:223-30.

18 Chae S, Desai S, Crowell M, et al. Characteristics of women obtaining induced abortions in selected low- and middle-income countries. PLoS One 2017;12:e0172976.

19 Sully E, Dibaba Y, Fetters T, et al. Playing it safe: legal and clandestine abortions among adolescents in Ethiopia. J Adolesc Health 2018;62:729-36.

20 Sully EA, Atuyambe L, Bukenya J, et al. Estimating abortion incidence among adolescents and differences in postabortion care by age: a cross-sectional study of postabortion care patients in Uganda. Contraception 2018;98:510-6.

21 Riley T, Madziyire MG, Chipato T, et al. Estimating abortion incidence and unintended pregnancy among adolescents in Zimbabwe, 2016: a cross-sectional study. BMJ Open 2020;10:e034736.

22 Coast E, Norris AH, Moore AM, et al. Trajectories of women's abortion-related care: a conceptual framework. Soc Sci Med 2018;200:199-210.
23 Singh S, Juarez F, Prada E, et al. Estimating abortion incidence: assessment of a widely used indirect method. Popul Res Policy Rev 2019;38:429-58

24 Harlap S, Shiono P, Ramcharan S. A life table of spontaneous abortions and the effects of age, parity and other variables. In: Porter I, Hook E, eds. Human embryonic and fetal death. New York, NY: Academic Press, 1980: 145-58.

25 Ministère du Plan et Suivi de la Mise en oeuvre de la Révolution de la Modernité (MPSMRM/Congo), Ministère de la Santé Publique (MSP/Congo), ICF International. Enquête Démographique et de Santé en République Démocratique Du Congo 2013-2014. Rockville, Maryland, USA: MPSMRM, MSP, and ICF International, 2014.

26 Institut National de la Statistique (INS). Annuaire Statistique 2014. Kinshasa, DRC: INS-RD Congo, 2015. Available: https://www. undp.org/content/dam/dem rep congo/docs/MDG/Anuaire\% 20Statistique\%20RDC\%202014.pdf [Accessed 9 Jul 2019].

27 Leridon H, Helzner J. Table 4.20 complete table of intrauterine mortality per 100 ova exposed to the risk of fertilization. In: Leridon $\mathrm{H}$, ed. Human fertility: the basic components. Chicago: University of Chicago Press, 1977: 81.

28 Li Z, Patton G, Sabet F, et al. Contraceptive use in adolescent girls and adult women in low- and middle-income countries. JAMA Netw Open 2020;3:e1921437.

29 Performance Monitoring and Accountability 2020 (PMA2020). PMA2020/Kinshasa, DRC: September-November 2017 (Round 6). Baltimore, MD: PMA2020. Available: https://pma2020.org/sites/ default/files/PMA2020-Kinshasa-DRC-R6-FP-Brief-En.pdf [Accessed 9 Jul 2019].

30 Chandra-Mouli V, Parameshwar PS, Parry M, et al. A never-before opportunity to strengthen investment and action on adolescent contraception, and what we must do to make full use of it. Reprod Health 2017; 14:85.

31 Paul M, Chalasani S, Light B. Contraception for adolescents and youth: responsive to their sexual and reproductive health needs and rights. UNFPA, 2019. https://www.unfpa.org/sites/default/files/ resource-pdf/AY_Contraception_11Nov_UnfpaFonts_v2.pdf

32 Mukendi DM, Mukalenge FC, Ali MM. Exploring the adequacy of family planning services to adolescents needs: results of a crosssectional study from two settings in the Democratic Republic of the Congo. Health Educ Public Health 2019;2:131-41.

33 Mbadu Muanda F, Gahungu NP, Wood F, et al. Attitudes toward sexual and reproductive health among adolescents and young people in urban and rural DR Congo. Reprod Health 2018;15:74.

34 Casey SE, Steven VJ, Deitch J, et al. "You must first save her life": community perceptions towards induced abortion and post-abortion care in North and South Kivu, Democratic Republic of the Congo. Sex Reprod Health Matters 2019;27:106-17.

35 Owolabi OO, Wong KLM, Dennis ML, et al. Comparing the use and content of antenatal care in adolescent and older first-time mothers in 13 countries of West Africa: a cross-sectional analysis of demographic and health surveys. Lancet Child Adolesc Health 2017;1:203-12.

36 Kwete D, Binanga A, Mukaba T, et al. Family planning in the Democratic Republic of the Congo: encouraging momentum, formidable challenges. Glob Health Sci Pract 2018;6:40-54.

37 Mpunga-Mukendi D, Mukalenge Chenge F, Ali Mapatano M, et al Assessing Comprehensive Sexuality Education Programs in the Democratic Republic of the Congo: Adolescents' and Teachers' Knowledge, Attitudes and Practices towards Contraception. Health 2020;12:1428-44. 